\title{
FITOTECNIA
}

\section{DIFERENTES MANEJOS DA COBERTURA VEGETAL DE AVEIA PRETA EM POMAR NO SUL DO BRASIL $\left(^{(\mathbf{1})}\right.$}

\author{
ANDREA DE ROSSI (2); LEO RUFATO ${ }^{(2)}$; CLEVISON LUIZ GIACOBBO ${ }^{(2)}$;VAGNER BRASIL COSTA ${ }^{(2)}$; \\ MAURÍCIO ROBERTO VITTI ${ }^{(2)}$; MARTA ELENA GONZALEZ MENDEZ ${ }^{(2)}$; \\ JOSÉ CARLOS FACHINELLO ${ }^{(2)}$
}

\begin{abstract}
RESUMO
O experimento foi implantado no Pomar Didático do Centro Agropecuário da Palma, da Faculdade de Agronomia Eliseu Maciel, Universidade Federal de Pelotas, com o objetivo de avaliar o efeito de diferentes manejos da cobertura vegetal de aveia preta sobre a porcentagem de água, temperatura, conteúdo de matéria orgânica e resistência à penetração do solo e ao grau de infestação de plantas daninhas em pomar. Os tratamentos constaram de diferentes técnicas de manejo da cobertura vegetal de solo com aveia preta: incorporação da aveia ao solo; dessecação com herbicida; acamamento com rolo faca; roçada a $5 \mathrm{~cm}$ e uma testemunha (solo descoberto). A semeadura da aveia foi realizada em abril de 2002 e a aplicação dos tratamentos, no fim do mês de agosto do mesmo ano. $\mathrm{O}$ experimento foi desenvolvido em blocos casualizados, com três blocos, cinco tratamentos e uma repetição. Os dados foram submetidos à analise da variância através do teste $\mathrm{F}$ e as médias comparadas pelo teste de Duncan. Nos tratamentos em que houve manutenção da cobertura vegetal no pomar, observaram-se redução da temperatura, aumento da umidade do solo e da resistência à penetração. $\mathrm{O}$ revolvimento do solo aumentou a diversidade de plantas daninhas. A incorporação da aveia preta, após 60 dias, teve o mesmo comportamento que o solo descoberto, quanto à umidade e temperatura do solo.
\end{abstract}

Palavras-chave: cobertura de solo, matéria orgânica, Avena strigosa, propriedades físicas do solo.

\section{ABSTRACT \\ DIFFERENT MANAGEMENT OF BLACK OAT CROP COVER ORCHARD FROM AT SOUTH OF BRAZIL}

The experiment was managed in the Didactic Orchard of the Agricultural Center of Palma, which belongs to the Federal University of Pelotas (UFPel). The treatments consisted of 5 different managements of black oat crop cover: incorporation of black oat to soil; chemical management with herbicide; lodging; mowing at $5 \mathrm{~cm}$ and control (uncovered soil). The sowing of the oat was accomplished by April of 2002 and the installation of the experiment, by the end of August of the same year. The analyzed variables were percentage of soil moisture at a depth of $15 \mathrm{~cm}$, temperature of the soil at a depth of $5 \mathrm{~cm}$, percentage of organic matter of the soil, soil resistance to the penetration and identification and degree of infestation by weeds. The experiment was managed in randomized blocks, with 3 blocks, 5 treatments and one repetition. The data were submitted to analysis of the variance through F test and the averages compared by Duncan Test. Maintenance of crop covering in orchard propitiated smaller temperature and larger soil moisture; the soil turn-over increased the diversity of weeds and the incorporation of black oat, after 60 days, had the same behavior as the uncovered soil.

Key words: soil covering, organic matter, Avena strigosa, soil physical properties..

( $\left.{ }^{1}\right)$ Recebido para publicação em 4 de julho de 2005 e aceito em 4 de abril de 2007.

$\left({ }^{2}\right)$ Departamento de Fitotecnia, Faculdade de Agronomia Prof. Eliseu Maciel, Universidade Federal de Pelotas, Caixa Postal 354, 96010-900 Pelotas (RS), Brasil. E-mail: derossiandrea@yahoo.com.br (*) Autora correspondente. 


\section{INTRODUÇÃO}

O manejo de pomares tem passado por notáveis modificações na última década. Se, no passado, as intervenções culturais eram direcionadas à maximização da produção, hoje os objetivos também são melhoria da qualidade do produto e maior integração entre a fruticultura e o ambiente (MARANGONi et al., 1995). As normas de Produção Integrada de Frutas preconizam técnicas de manejo do solo que maximizem seu potencial natural e reduzam os aportes externos. A cobertura vegetal se propõe como alternativa ecológica e econômica de manejar o solo e sua adoção propicia redução progressiva no consumo energético (Rufato, 2004).

Segundo Almeida (1991), a cobertura vegetal melhora as características físicas, químicas e biológicas do solo. No que diz respeito a plantas daninhas, modifica a constituição qualitativa e quantitativa do complexo florístico que se desenvolve no terreno, por interferir no processo de quebra de dormência das sementes e pela sua ação alelopática sobre a germinação e o desenvolvimento das plântulas.

Para Adegas (1997), a cobertura morta mantida na superfície, funciona como elemento isolante, reduzindo a amplitude térmica e hídrica no solo e filtrando os feixes de luz de ondas longas. O processo de germinação das plantas daninhas estando intimamente ligado a esses fatores, reduz-se substancialmente no solo com grande quantidade de cobertura morta, que, ao se decompor em superfície, libera gradativamente uma série de compostos orgânicos, denominados aleloquímicos, os quais interferem diretamente na germinação e emergência das plantas daninhas.

Porto et al. (1995) observaram que a permanência de restos culturais em superfície favorece não só o controle de erosão, mas também o armazenamento de água em superfície no perfil do solo e ainda exerce efeito favorável sobre a temperatura. A temperatura determina as taxas de evaporação e aeração do solo, assim como o tipo e a intensidade das reações químicas (Hillel, 1998). A cobertura vegetal contribui para melhorar a infiltração de água, evitar e diminuir a lixiviação de nutrientes, manter a temperatura do solo mais estável e diminuir a incidência de plantas daninhas. Estudos recentes como os de Gomes (2003) e Rufato (2004) têm indicado a cobertura vegetal de aveia preta como alternativa positiva à aração do solo em pomares, porém estudos sobre o manejo mais adequado dessa cobertura vegetal são ainda incipientes.
Neste trabalho, a hipótese é a de que os diferentes manejos dados à cobertura vegetal de aveia preta podem alterar características importantes do solo e a presença de plantas infestantes. BRAGAGNOLO e MielniczuK (1990) afirmam que, além da quantidade de material vegetal sobre o solo, seu manejo deve ser considerado. Além disso, STRECK et al. (1994) afirmam que a conformação e o arranjo da cobertura sobre o solo, bem como o efeito direto do implemento, afetam características como recobrimento do solo, regime de temperatura e a conservação da água no solo. Para Buhler (1995) e Pitelli (1985) as comunidades de plantas infestantes também podem ser afetadas pelo manejo da cobertura vegetal, favorecendo ou desfavorecendo espécies. Portanto, este trabalho teve por objetivo avaliar o efeito de diferentes manejos da cobertura vegetal de aveia preta sobre a porcentagem de água, temperatura, conteúdo de matéria orgânica, resistência à penetração do solo e o grau de infestação de plantas daninhas em pomar no Sul do Brasil.

\section{MATERIAL E MÉTODOS}

O experimento foi implantado no Pomar Didático do Centro Agropecuário da Palma, da Faculdade de Agronomia Eliseu Maciel, Univesidade Federal de Pelotas, em Argissolo Vermelho-Amarelo, em pomar de pereira cv. Garber, com espaçamento de $3 \mathrm{~m} \times 4 \mathrm{~m}$. Os tratamentos constaram de diferentes técnicas de manejo da cobertura vegetal de solo com aveia preta: incorporação da aveia ao solo com o emprego de capina manual em profundidade; dessecação com herbicida, com aplicação realizada com pulverizador costal; acamamento, realizado com um tronco, simulando o efeito de rolo faca; roçada a $5 \mathrm{~cm}$, realizada com roçadeira manual, deixando o material vegetal cortado sobre a superfície do solo, além de uma testemunha (solo descoberto, sem plantio de aveia preta e mantido sem vegetação por meio de capina manual superficial). A semeadura da aveia foi realizada em abril de 2002 e a aplicação dos tratamentos, no fim de agosto do mesmo ano (quando a aveia estava no estágio de grão leitoso). Cada parcela tinha dimensão de 1,5 m x 1,5 m, com bordadura de 0,25 m. Anteriormente à instalação do experimento, foi realizada coleta de material vegetal da cobertura, em área de $0,5 \times 0,5 \mathrm{~cm}$, para estimativa da biomassa verde por hectare da parte área e da massa do sistema radicular da aveia preta. Também foram coletadas amostras de solo da área do experimento para determinação da porcentagem de matéria orgânica inicial. A biomassa verde inicial da parte aérea e do sistema radicular era, respectivamente, de 46,04 e 7,24 t.ha ${ }^{-1}$ e o conteúdo de matéria orgânica de solo, de 20,8 g. $\mathrm{kg}^{-1}$. 
As variáveis analisadas foram: porcentagem de água do solo a $15 \mathrm{~cm}$ de profundidade, temperatura do solo a $5 \mathrm{~cm}$ de profundidade, expressa em graus centígrados, conteúdo de matéria orgânica do solo, resistência à penetração do solo de zero a 0,6 $\mathrm{m}$ de profundidade, expressa em MPa e identificação e grau de infestação de plantas daninhas. Para as duas primeiras variáveis, as coletas e leituras foram realizadas, a partir da instalação do experimento, a cada quatro dias, sempre às 14 horas. Para determinação da temperatura do solo foram instalados termômetros de bulbo em cada parcela, a $5 \mathrm{~cm}$ de profundidade; a porcentagem de água do solo foi obtida por diferença de massa. A avaliação do conteúdo de matéria orgânica foi realizada em amostras coletadas quinzenalmente por meio do método colorimétrico (TEDESCO et al., 1995). Na última data de avaliação do experimento (9/12/2002), realizou-se a análise da resistência do solo à penetração com o emprego de penetrômetro de impacto modelo IAA/Planalsucar/Stolf, em cinco pontos separados em cada repetição, até a profundidade de $0,6 \mathrm{~m}$. Os dados relativos à umidade do solo naquela data, para cada um dos tratamentos, são apresentados na Figura 2. O grau de infestação de plantas daninhas foi avaliado em uma área de 0,5 x 0,5 m em cada parcela, sendo utilizada uma escala de notas para expressar a porcentagem de área coberta por plantas daninhas, do seguinte modo: 1 de $20 \%$ a $40 \%$; 2 - de $40 \%$ a $60 \%$; 3 - de $60 \%$ a $80 \%$ e 4 - de $80 \%$ a $100 \%$.

O experimento foi desenvolvido em blocos casualizados, com três blocos, cinco tratamentos, totalizando 15 unidades experimentais. Os dados foram submetidos à analise da variância através do teste $\mathrm{F}$ e as médias comparadas pelo Teste de Duncan ao nível de $1 \%$. As diferenças entre profundidades não foram analisadas estatisticamente.

\section{RESULTADOS E DISCUSSÃO}

Observou-se que no tratamento em que a aveia preta foi mantida roçada, ocorreu maior umidade do solo enquanto no solo descoberto a umidade do solo foi significativamente inferior aos demais tratamentos. $\mathrm{Na}$ incorporação, na dessecação e no acamamento da aveia preta, observaram-se valores intermediários de umidade do solo, sem diferenças significativas entre si, porém superiores ao do solo descoberto (Figura 1).

Nos períodos em que a precipitação pluvial foi baixa ou inexistente, observou-se que o aumento de água do solo descoberto foi sempre inferior aos demais tratamentos (Figura 2).

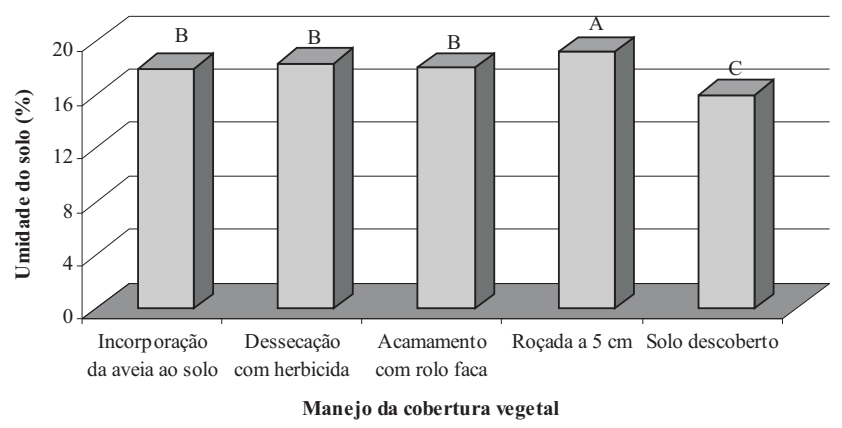

Figura 1. Umidade do solo a $15 \mathrm{~cm}$ de profundidade em função dos diferentes manejos da cobertura vegetal de aveia preta (média de 25 avaliações).

* Letras distintas diferem entre si pelo Teste de Duncan $(\alpha=0,01)$

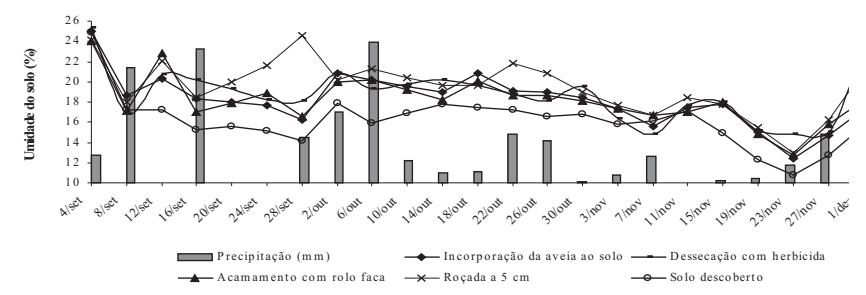

Figura 2. Variação da umidade do solo a $15 \mathrm{~cm}$ de profundidade em função dos diferentes manejos da cobertura vegetal de aveia preta e valores de precipitação pluvial no período de estudo.

A temperatura do solo a $5 \mathrm{~cm}$ de profundidade foi significativamente afetada pelo manejo da cobertura vegetal de aveia preta. No solo descoberto, os resultados de temperatura média foram superiores, enquanto a menor temperatura foi obtida quando a aveia preta foi mantida roçada, não diferindo, porém, do tratamento com aveia preta acamada (Figura 3). As temperaturas elevadas no solo favorecem a degradação da matéria orgânica, bem como a diminuição dos agregados do solo e sua resistência física, facilitando o carregamento superficial de solo pela água da chuva. DERPSCH et al. (1991), utilizando resíduos de aveia preta, constataram menor amplitude na temperatura, na profundidade de $3 \mathrm{~cm}$, em plantio direto, quando comparado ao plantio convencional, situação em que a temperatura do solo alcançou $45^{\circ} \mathrm{C}$. 




Figura 3. Temperatura do solo a $5 \mathrm{~cm}$ de profundidade em função dos diferentes manejos da cobertura vegetal de aveia preta (média de 25 avaliações).

* Letras distintas diferem entre si pelo Teste de Duncan $(\alpha=0,01)$

No decorrer do período de estudo (Figura 4), pode-se observar que na testemunha, além da temperatura média do solo ter sido maior, houve maior variação dessa temperatura em função da temperatura ambiente, enquanto nos tratamentos em que a aveia preta era mantida sobre a superfície, a variação diária da temperatura foi menor. Nos tratamentos em que a aveia preta foi mantida em superfície, observou-se a manutenção da proteção térmica do solo por um período mais prolongado, enquanto no tratamento com incorporação da aveia ao solo, a proteção térmica deixou de ser eficiente, provavelmente devido à rápida decomposição da palha restante no solo, expondo-o completamente.



Figura 4. Variação da temperatura do solo a $5 \mathrm{~cm}$ de profundidade em função dos diferentes manejos da cobertura vegetal de aveia preta.
A porcentagem de matéria orgânica do solo variou de $2,25 \%$ a $2,39 \%$, porém sem diferença estatística entre os tratamentos (Figura 5). Quando se faz a comparação do percentual de matéria orgânica inicial com o percentual alcançado ao final do experimento observa-se que houve um incremento expressivo nesse percentual para todos os tratamentos. Seria esperada uma redução no teor de matéria orgânica quando a cobertura foi incorporada ao solo por motivo de maior atividade da biomassa microbiana que consome matéria orgânica em seu metabolismo. Esse efeito não foi evidenciado, possivelmente, pelo curto tempo do experimento. Segundo ADEgAS (1997), ao realizar-se a incorporação dos resíduos vegetais com o preparo do solo, no sistema convencional, favorece-se o arejamento, que, por sua vez acelera a atividade microbiana e, conseqüentemente, a rápida decomposição desses resíduos. Por esse motivo, o conteúdo de matéria orgânica nas áreas de solos não revolvidos (plantio direto), normalmente, é maior que nas áreas de preparo convencional.

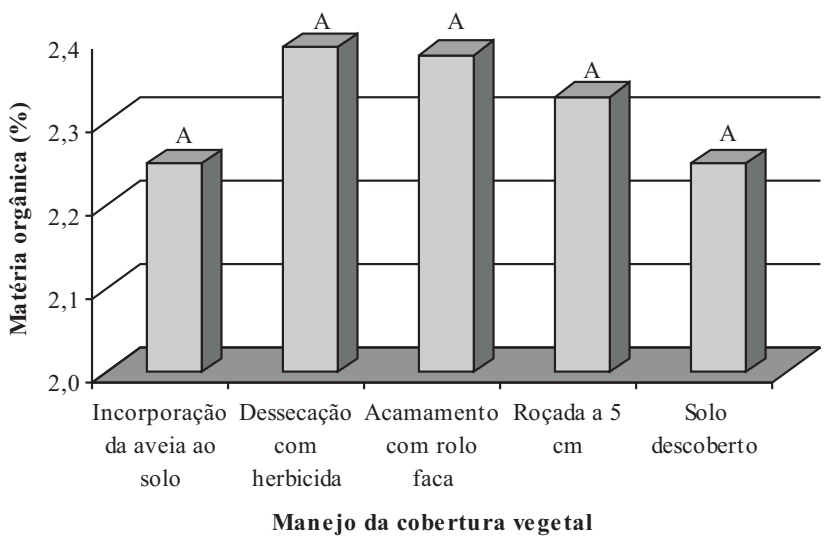

Figura 5. Porcentagem de matéria orgânica do solo em função dos diferentes manejos da cobertura vegetal de aveia preta.

* Letras distintas diferem entre si pelo Teste de Duncan $(\alpha=0,01)$

Com relação à resistência mecânica do solo à penetração, observou-se que no tratamento de roçada a $5 \mathrm{~cm}$ de profundidade houve maior resistência mecânica, seguido pelo tratamento de incorporação da aveia ao solo. $\mathrm{O}$ tratamento que resultou em menor resistência foi o solo descoberto. De modo geral, nas parcelas dos tratamentos onde se manteve o material vegetal em superfície verificou-se maior resistência à penetração (Figura 6). 


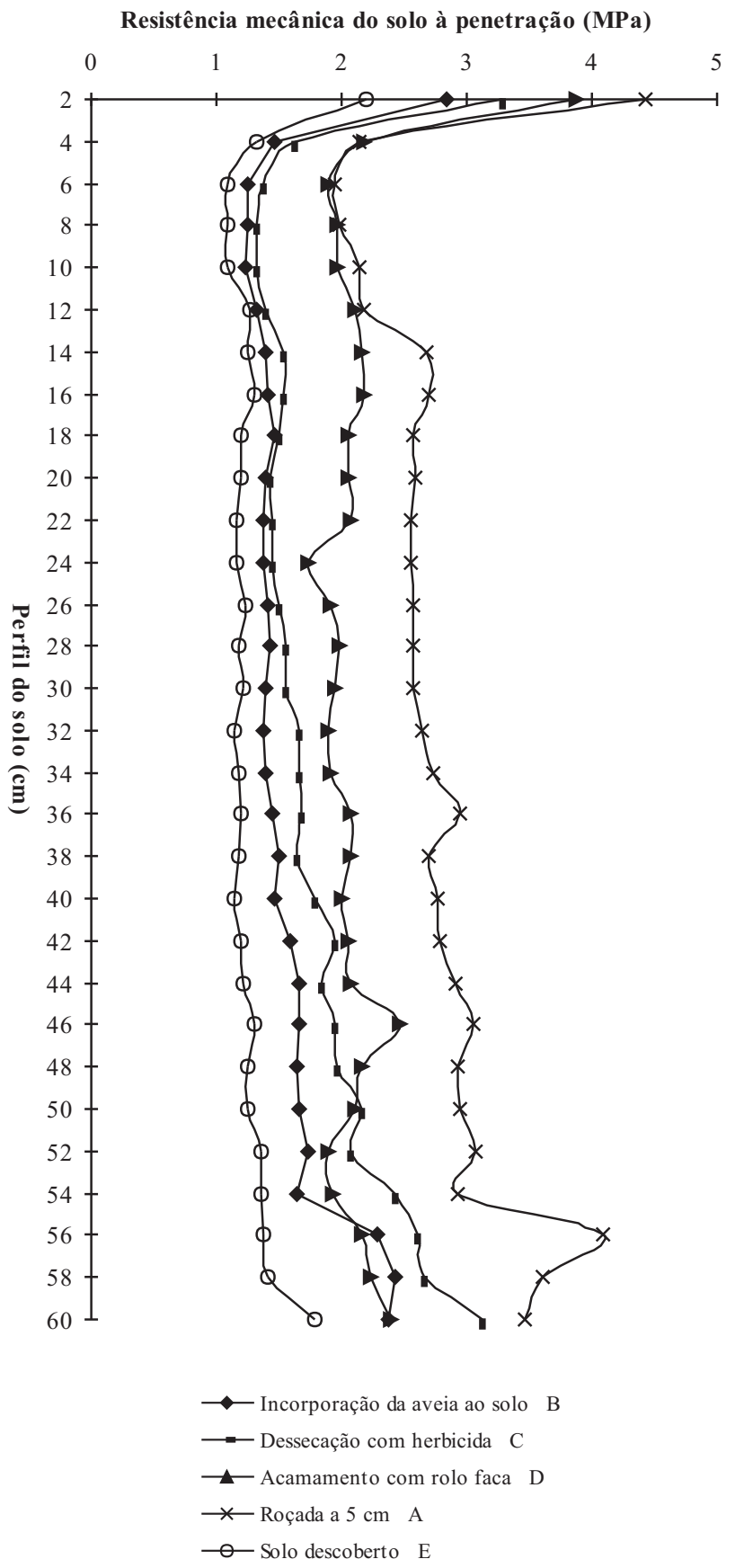

Figura 6. Resistência mecânica do solo à penetração em função dos diferentes manejos da cobertura vegetal de aveia preta.

* Letras distintas diferem entre si pelo Teste de Duncan $(\alpha=0,01)$

Para SoAne (1990), o aumento da resistência do solo está associado ao aumento da coesão pelos compostos orgânicos entre as partículas e agregados, ao estabelecer um cimento orgânico sobre e entre eles. Além disso, as raízes e hifas de fungos melhoram a resistência à deformação do solo através do entrelaçamento de partículas. Neste trabalho, pode-se observar que a supressão da cobertura de solo (solo descoberto) resultou em menor resistência à penetração dentre todos os tratamentos.

Com relação ao grau de infestação de plantas daninhas, pode-se observar que na testemunha tal grau foi estatisticamente superior ao dos demais tratamentos, somente não diferindo do tratamento com aveia preta acamada (Tabela 1). FERREIRA et al. (2000) observaram que, dentre várias espécies de cobertura vegetal estudadas, a aveia preta e a colza, propiciaram controle quase total das ervas, devido ao seu efeito alelopático.

Quanto à diversidade de espécies presentes nos tratamentos, observou-se maior diversidade de espécies infestantes onde houve revolvimento do solo (tratamento de incorporação da aveia preta) (Tabela 1). De acordo com Almeida e Rodrigues (1985), a existência de cobertura vegetal e a nãomovimentação reduzem o grau de infestação. De acordo com Igue (1984), a incorporação de restos vegetais pode produzir substâncias tóxicas durante sua decomposição, afetando a germinação de sementes de certas espécies, bem como a produção de substâncias estimulantes da germinação.

Para Medeiros (1990), o uso de cobertura verde e de restos vegetais, visando ao controle de plantas daninhas, é um exemplo muito antigo do aproveitamento econômico da alelopatia, pois além da supressão das plantas daninhas, exerce importante efeito na conservação do solo e na manutenção de sua umidade. O mesmo autor salienta, ainda, que o uso contínuo de uma mesma espécie como cobertura de solo, pode afetar o desenvolvimento de determinadas culturas agrícolas, devido ao acúmulo de substâncias alelopáticas.

\section{CONCLUSÕES}

1) A manutenção da cobertura vegetal do solo com aveia preta no pomar proporciona menor variação da temperatura e maior retenção de água no solo.

2) O revolvimento do solo aumenta a diversidade de plantas daninhas.

3) A incorporação da aveia preta, após 60 dias, tem o mesmo comportamento que o solo descoberto, quanto à umidade e temperatura do solo. 
Tabela 1. Espécies infestantes presentes e grau de infestação do solo conduzido em diferentes manejos da cobertura vegetal de aveia preta em pomares

\begin{tabular}{|c|c|c|c|c|c|c|}
\hline $\begin{array}{l}\text { Espécie } \\
\text { Nome científico }\end{array}$ & Nome comum & Incorporação & $\begin{array}{c}\text { Dessecação } \\
\text { da aveia }\end{array}$ & $\begin{array}{c}\text { Acamamento } \\
\text { herbicida }\end{array}$ & $\begin{array}{c}\text { Roçada a } \\
5 \mathrm{~cm}\end{array}$ & $\begin{array}{c}\text { Solo } \\
\text { descoberto } \\
\end{array}$ \\
\hline Avena strigosa & Aveia preta & $x$ & & & & \\
\hline Bidens pilosa & Picão preto & $x$ & $x$ & $x$ & $x$ & \\
\hline Brachiaria plantaginea & Papua & & & & & $x$ \\
\hline Crysantemun myconis & Mal-me-quer & $x$ & & $x$ & & $x$ \\
\hline Cynodon dactylon & Grama seda & $x$ & & $x$ & $x$ & $x$ \\
\hline Cyperus rotundus & Tiririca & $x$ & $x$ & $x$ & $x$ & $x$ \\
\hline Eleusine indica & Pé-de-galinha & $x$ & & $x$ & & \\
\hline Erechtites hieraciifolius & Erva gorda & & $x$ & $x$ & $x$ & $x$ \\
\hline Galinsoga parviflora & Picão branco & & & & & $x$ \\
\hline Hyptis lophanta & Hortelã & $x$ & $x$ & & $x$ & \\
\hline Lolium multiflorum & Azevém & $x$ & & $x$ & $x$ & \\
\hline Oxalis oxyptera & Azedinha & $x$ & $x$ & $x$ & & \\
\hline Plantazo tomentosa & Tanchagem & $x$ & & & & \\
\hline Polygonum convolvulus & Cipó de veado & $x$ & & & & $x$ \\
\hline Portulaca oleraceae & Beldroega & $x$ & & & & \\
\hline Raphanus raphanistrum & Nabo & & & & & $x$ \\
\hline Richardia brasiliensis & Poaia & $x$ & $x$ & & $\mathrm{x}$ & $\mathrm{x}$ \\
\hline Rumex obtusifolis & Língua de vaca & $x$ & & & & \\
\hline Sida rhombifolia & Guanxuma & $x$ & & $\mathrm{x}$ & & $\mathrm{x}$ \\
\hline Solanum americanum & Maria pretinha & & & $x$ & & \\
\hline Sonchus oleraceus & Serralha & & $x$ & $x$ & $x$ & $x$ \\
\hline Spergula arvensis & Gorga & & & & & $x$ \\
\hline Stachys arvensis & Orelha de urso & $x$ & & & $x$ & $x$ \\
\hline \multicolumn{2}{|c|}{ Grau de infestação $(\alpha=0,01)$} & $1.57 \mathrm{~B}$ & $1.00 \mathrm{~B}$ & $2.65 \mathrm{AB}$ & $1.00 \mathrm{~B}$ & $3.65 \mathrm{~A}$ \\
\hline
\end{tabular}

$\mathrm{x}=$ Ocorrência

\section{REFERÊNCIAS}

ADEGAS, A.S. Manejo integrado de plantas daninhas. In: CONFERÊNCIA ANUAL DE PLANTIO DIRETO, 2., 1997, Pato Branco. Anais... Passo Fundo: Aldeia Norte, 1997. p. 17-26.

ALMEIDA, F. S.; RODRIGUES, B. N. Plantio direto. In: ALMEIDA, F. S.; RODRIGUES, B. N. Guia de herbicidas: contribuição para o uso adequado em plantio direto e convencional. Londrina: IAPAR, 1985. p. 341-399.

ALMEIDA, F.S. Controle de plantas daninhas em plantio direto. Londrina: IAPAR, 1991. 34p.

BUHLER, D.D. Influence of tillage sistems on weed population dynamics and management in corn and soybean in the central USA. Crop Science, Madison, v. 35, p. 1247-1258, 1995.
BRAGAGNOLO, N., MIELNICZUK, J. Cobertura do solo por palha de trigo e seu relacionamento com a temperatura e umidade do solo. Revista Brasileira de Ciência do Solo, Campinas, v. 14, p. 369-374, 1990.

DERPSCH, R.; ROTH, C.H.; SIDIRAS, N. \& KÖPKE, U. Controle da erosão no Paraná, Brasil: Sistemas de cobertura do solo, plantio direto e preparo conservacionista do solo. Eschborn,: GTZ, 1991.

FERREIRA, T. N.; SCHWARZ, R. A; STRECK, E. V. Solos: manejo integrado e ecológico: elementos básicos. Porto Alegre: EMATER/ RS, 2000. 95p.

GOMES, F. R. C. Qualidade da fruta e do solo em pomares de pessegueiro manejados com aveia preta (PIP). 2003. $84 \mathrm{f}$. Tese (Doutorado em Ciências) - Departamento de Fitotecnia, Universidade Federal de Pelotas, Pelotas, 2003. 
HILLEL, D. Environmental soil physics. New York: Academic Press, 1998. 770 p.

IGUE, K. Dinâmica da matéria orgânica e seus efeitos nas propriedades do solo: In: FUNDAÇÃO CARGILL. Adubação Verde no Brasil. Campinas: Fundação Cargill, 1984. p. 232-267.

MARANGONI, B.; SCUDELLARI, D.; TACLIAVINI, M. Relazione tra nutrizione azotata e metabolismo delle piante. Rivista di Frutticoltura e di Ortofloricoltura, Bologna, v. LVII p.7-8, 1995.

MEDEIROS, R. M. Alelopatia: importância e suas aplicações. HortiSul. Pelotas: EMBRAPA/CNPFT, v. 1, n. 3, 1990.

PITELLI, R.A. Interferência das plantas daninhas em culturas agrícolas. Informe Agropecuário, Belo Horizonte, v.11, n. 129, p.16-27, 1985.

PORTO, O.M., RECK, S.R., MORAES, L.A.H. et al. Recomendações técnicas para a cultura de citrus no Rio Grande do Sul. Porto Alegre: FEPAGRO, 1995. (Boletim FEPAGRO)
RUFATO, L. Indicadores da qualidade biológica do solo e coberturas vegetais para a cultura do pessegueiro (Prunus persica L. Batsch) em produção integrada e orgânica. 2004. 101 f. Tese (Doutorado em Ciências) - Departamento de Fitotecnia, Universidade Federal de Pelotas, 2004.

SOANE, B.D. The role of organic matter in soil compactability: a review of some practical aspects. Soil Tillage Research, 16:179-201, 1990.

STRECK, N.A., SCHNEIDER, F.M., BURIOL, G A. Modificações físicas causadas pelo mulching. Revista Brasileira de Agrometeorologia, Santa Maria, v.2, p.131-142, 1994.

TEDESCO, M.J., GIANELLO, C., BISSANI, C. A. et al. Análise de solo, plantas e outros minerais. Porto Alegre: Departamento de Solos - Faculdade de Agronomia, UFRGS, 1995. 174p. 